\title{
Entre hinos, bandeiras e heróis: imigração européia, classe operária e a constituição da nacionalidade nos grupos escolares da cidade de Santos
}

\author{
André Luiz Rodrigues Carreira*
}

\begin{abstract}
Resumo
O presente estudo analisa, em uma perspectiva histórica, o papel exercido pelo sistema público de educação no Estado de São Paulo nas primeiras décadas do século XX na incorporação e assimilação da população estrangeira, majoritariamente europeia, vinculada ao movimento operário. A investigação utilizará como estudo de caso a cidade portuária de Santos, no litoral paulista, município caracterizado por expressivo contingente de imigrantes provenientes da Península Ibérica e pela presença de combativa classe operária, principalmente associada a atividades portuárias e à construção civil. A pesquisa tem por objetivo discutir o espaço ocupado pelas iniciativas estatais de educação popular em Santos durante as décadas de 1910 e 1920 e a sua relação com o discurso, traduzido em políticas públicas, nacionalista de absorção do estrangeiro pertencente à classe trabalhadora. O estudo procura ainda analisar as formas de resistência encontradas pelos destinatários das ações reformistas do período, dentro e fora dos muros das instituições escolares.
\end{abstract}

Palavras-chave: educação popular; classe trabalhadora; imigração europeia.

\section{Among hymns, flags and heroes: European immigration, working class and the establishment of nationality in school groups of Santos city}

\begin{abstract}
\section{A "Barcelona Brasileira": a imigração e a formação da classe operária santista}

This study analyzes, from a historical perspective, the role played by public education system in the state of Sao Paulo in the first decades of the twentieth century in the incorporation and assimilation of the foreign population, mostly European, linked to the labor movement. The research developed a case study of the port city of Santos, on the coast, municipality wherein significant number of immigrants from the Iberian Peninsula and the presence of militant working class, mainly associated with port activities and construction. The research aims to discuss the space occupied by state initiatives for popular education in Santos during 1910s and 1920s and their relationship with the speech, translated into public policy, foreign absorption nationalist working-class. The study seeks to analyze the forms of resistance encountered by the recipients of the reformist actions of the period, both inside and outside the walls of educational institutions.

Keywords: popular education; working class; European immigration.

A cidade de Santos do início do período republicano é um dos casos paradigmáticos das transformações pelas quais passava um país independente que procurava inserir-se nos marcos internacionais do desenvolvimento capitalista tanto do ponto de vista das relações econômicas quanto pela incorporação de doutrinas, valores e modos de vida. Santos era, a partir de fins do século XIX, o maior porto do país e escoadouro da maior riqueza nacional, o café.

A riqueza proporcionada pelo café, as reformas de modernização no porto, o combate às epidemias que assolavam a cidade $e$ as transformações urbanas impulsionadas pelo sanitarismo haviam criado condições mínimas à fixação de grande contingente de imigrantes europeus que inundaram Santos naqueles anos, modificando sensivelmente a estrutura social da cidade. Pelo censo de 1913, podemos ter uma ideia do impacto dos fluxos migratórios. Em uma população de 88.967 habitantes, $86,6 \%$ da população total era composta de brancos. Os estrangeiros representavam $42,5 \%$ da população total da cidade - chegando a $54 \%$ da população masculina -, sendo o maior contingente formado por portugueses, espanhóis e italianos.

A definição da cidade como "porto do café" e o acelerado crescimento populacional vinculado ao processo de urbanização impulsionado pelas reformas sanitaristas e portuárias alteraram profundamente a estrutura demográfica e socioeconômica de Santos. No lugar dos cortiços e das epidemias, surgiam os canais, as amplas praças e largas avenidas, signos de uma modernidade importada do Velho Mundo.

\footnotetext{
* Endereço eletrônico: andrecarreira80@ hotmail.com
} 
Em pouco tempo, a inspiradora Europa idealizada pelas classes dominantes iria se chocar com a visão dos europeus, imigrantes e trabalhadores, que por aqui chegavam aos milhares. O modelo do que se entendia por "civilização" daria lugar à concepção do estrangeiro "agitador" e indesejado.

A formação da classe operária em Santos, entendida aqui sob a perspectiva de Thompson (2011) de formação como um processo ativo que se deve tanto aos condicionamentos como pela ação humana cotidiana, começa a ser percebida a partir do surgimento das primeiras greves, ainda na segunda metade do século XIX. Entre as décadas de 1870 e 1880, carregadores de café, trabalhadores da construção civil e trabalhadores do porto de Santos paralisariam as suas atividades e, em 1891, a cidade presenciaria a primeira greve geral de nível local no país (GITAHY, 1992).

A organização operária adquire concretamente seus primeiros contornos a partir de 1904 com a fundação da Sociedade Primeiro de Maio, formada exclusivamente por trabalhadores da construção civil. Alguns meses depois, com a pretensão de congregar operários de diversas áreas, é criada a Sociedade Internacional União dos Operários. Embora fundada majoritariamente por trabalhadores ligados ao café, a Internacional teria, em pouco tempo, milhares de associados. As paralisações e a reação repressiva da polícia tornamse cada vez mais frequentes.

Em abril de 1906, no Rio de Janeiro, aconteceria o Congresso Operário, elemento chave para a compreensão das influências ideológicas e das formas de ação adotadas pela classe operária santista naquele momento. $\mathrm{O}$ anarcossindicalismo, rejeitando a participação política formal e o envolvimento em questões religiosas e defendendo a jornada de trabalho de oito horas diárias, passa a ser predominante no movimento operário da cidade de Santos. (GITAHY, 1992) As greves pelas oito horas de trabalho se espalham por diversas categorias profissionais da cidade. Em 1907, em assembleia geral, é criada a Federação Operária Local de Santos (FOLS), composta pelos sindicatos de pedreiros, carpinteiros, pintores, funileiros, carregadores de café e tecelões. Ligada ao anarcossindicalismo, a FOLS seria, ao lado da Internacional, responsável pela articulação de grande parte das greves que irrompem no período.

As razões da força do anarcossindicalismo em Santos podem ser explicadas da seguinte forma: em primeiro lugar, trata-se de uma cidade repleta de imigrantes (muitos trazendo da Europa essas idéias), onde o apelo ao internacionalismo tinha sentido prático imediato, ou seja, a quebra das rivalidades nacionais. Por outro lado, o elevado número de operários, especialmente no porto, favorecia a organização de sindicatos, objetivo da ideologia anarquista que, rechaçando a participação política em partidos ou no Parlamento (algo inclusive inacessivel em um sistema elitista e fechado como no Brasil da República Velha), percebia o movimento sindical como forma concreta de emancipação dos trabalhadores (GONÇALVES, 1995).

O histórico de lutas e resistência reforçava o mito da "Barcelona Brasileira", forjado nas precárias condições de trabalho, nos baixos salários, na violência da repressão e das deportações, mas também nas greves, na organização e na combatividade da classe operária local.

A capacidade de mobilização dos trabalhadores da cidade, concentrados principalmente nas atividades vinculadas ao porto, à infraestrutura urbana e à construção civil, pode ser explicada pela concepção de que em Santos:

não havia fábricas colossais tão difíceis de organizar. No setor de construção $e$ transportes, áreas em que o sindicalismo já obtivera sucesso considerável, a maioria dos trabalhadores era de adultos do sexo masculino. $E$ talvez os imigrantes portugueses e espanhóis da cidade já tivessem encontrado seus laços comuns, dos quais careciam os portugueses e brasileiros no Rio de Janeiro $e$ os italianos $e$ portugueses em São Paulo (MARAM, 1979).

A questão étnica na composição da sociedade e da classe operária santista é fator fundamental para a compreensão das relações que se passavam na cidade, inclusive nas iniciativas ligadas à instrução popular, nos primeiros anos do século que se iniciava naquele momento. Ainda segundo Sheldon Maram (1979), o expressivo contingente de portugueses radicados em Santos, em especial os portuários e trabalhadores da construção civil, teria tido participação decisiva para a força organizacional dos sindicatos de Santos. O autor aponta que o papel exercido pelos 

nacionalidade nos grupos escolares da cidade de Santos

espanhóis foi também significativo. Embora numericamente inferiores, os espanhóis teriam ocupado os quadros de liderança no operariado santista. (MARAM, 1979) Portugueses e, primordialmente, espanhóis, fariam de Santos "um dos mais importantes representantes do sindicalismo revolucionário, com propostas concretas de defesa do anarquismo" (SARTI, 1981).

No entanto, é preciso cuidado ao extrair das características econômicas da cidade e da composição social dos trabalhadores relações diretas com o comportamento político e ideológico da classe operária local. A presença marcante de imigrantes na formação do operariado de Santos não fez de sua classe operária algo coeso e homogêneo. A existência de diferentes entidades representativas dos trabalhadores da cidade, como a FOLS, a Internacional, a Primeiro de Maio e diversos sindicatos autônomos, assim como as distintas formas de ação utilizadas pelas categorias profissionais existentes em Santos evidenciam o caráter complexo do movimento operário santista. Entre a "ação direta" e o "reformismo", milhares de sujeitos, trabalhadores, lutavam por condições reais e objetivas de existência.

Em publicação de junho de 1911, o periódico local $O$ Proletário dá mostras das especificidades das condições de trabalho das diferentes categorias profissionais da cidade. Enquanto os sindicatos da construção civil haviam assegurado o seu reconhecimento (closed shop) e a jornada diária de oito horas de trabalho, a situação dos trabalhadores do Saneamento, ligados ao governo do Estado, era descrita nos seguintes termos:

enquanto nas obras particulares se trabalha oito horas, lá sendo uma repartição pública os trabalhadores são forçados a trabalhar onze ou doze horas por dia. Quem conhece aquele serviço sabe perfeitamente o quanto ele é nocivo à saúde e quanto é repugnante. Mas mais revoltante é o salário. (...) Enquanto os engenheiros e chefes recebem somas fabulosas, os trabalhadores comem um muito rude pedaço de pão de modo a não morrer de fome. São insultados pelos feitores que são canalhas. A imprensa de grande formato se desfaz em elogios a essa Comissão (de Saneamento), esquecendo-se de que esses serviços estão sendo prestados por todos que lá trabalham, vegetando na mais negra miséria. (GITAHY, 1992).
O fragmento acima nos proporciona elementos interessantes para a discussão da contraditória sociedade que se configurava na cidade de Santos no princípio do século. As reformas urbanas de caráter sanitarista, entoadas em verso e prosa por parte da imprensa local, são retratadas aqui sob o prisma de quem cotidianamente a tornou possível. O caminho rumo à modernidade escondia em si os tortuosos obstáculos da exploração do trabalho.

Os últimos anos da primeira década do século XX e o início da década de 1910 são anos difíceis para o operariado santista. A violenta repressão de 1908 promovida por iniciativa da Companhia Docas sobre os portuários grevistas, contando inclusive com a atuação de fuzileiros navais e tropas de infantaria e cavalaria, e o subsequente desemprego decorrente da crise econômica do período levaria o movimento operário da cidade a aglutinar-se na Federação Operária Local de Santos em torno dos trabalhadores da construção civil.

De orientação libertária, a FOLS também entraria em declínio com a forte repressão ao movimento operário em 1913 e 1914 e com a conjuntura da Primeira Guerra Mundial que se iniciava. Entretanto, apenas esses fatores não respondem às dificuldades da classe operária santista em meados da década de 1910. Em estudo sobre os trabalhadores de Santos no entreguerras, Fernando Teixeira da Silva (2003) destaca que as divisões internas, as diferentes concepções sobre o papel dos sindicatos na sociedade e as rivalidades e disputas no campo ideológico entre a até então hegemônica corrente anarcossindicalista e os "reformistas" também tiveram um peso relevante nesse processo. Sobre os adeptos do chamado "anarcossindicalismo de ação direta", o autor aponta que:

por trás da aparente homogeneidade e sinominia que envolve as denominações "sindicalismo libertário", "anarquista" $e$ "revolucionário" escondem-se diversas concepções que, certamente, guardam pontos em comum, mas também apresentam diferenças e engendram divisões e conflitos no movimento sindical. Muitos anarquistas privilegiavam difundir as doutrinas ácratas nos sindicatos, enquanto os reformistas proclamavam a necessidade de representação política dos operários. Já os sindicalistas revolucionários (...) escreviam 
em 1919 sobre a necessidade de organização como o único meio eficaz pelo qual o operariado pode conseguir o seu desideratum numa sociedade nova, livre e igualitária (SILVA, 2003).

Em 1917, quando ocorre a greve geral em São Paulo, marco do movimento sindical do país, os operários de Santos aderem e, em solidariedade, cruzam os braços, paralisando parcialmente a cidade. Entretanto, a reorganização sindical em Santos só ocorreria após o término da guerra e, em 1919, treze categorias entrariam novamente em greve. Apesar da ampla adesão à paralisação de 1919, o sindicalismo de ação direta, mais comum entre os trabalhadores da construção civil, entraria nos anos 1920 profundamente abalado. A repressão patronal e policial, as deportações e condenações de lideranças associados a um nacionalismo xenófobo que despontava no pós-guerra contribuíam para a decadência dessa forma de organização. Era preciso incorporar o estrangeiro "perigoso", "nocivo" à constituição da nacionalidade. Essa incorporação, pela força, pela lei, ou pelas letras, encontraria no discurso educacional do período um de seus pontos centrais.

Quase três décadas haviam se passado e os sonhos da República redentora do imaginário das elites intelectuais haviam se esvaído na heterogeneidade de uma sociedade configurada pela maciça presença de imigrantes e pelas "agitações" operárias. Em meio a uma onda de nacionalismo influenciada pela Primeira Guerra Mundial, a educação volta à cena. À escola cabia o pouco modesto papel de incorporação do estrangeiro indesejado e de construção da identidade do povo brasileiro. Ordenar, civilizar, assimilar, disciplinar se tornam palavras comuns ao vocabulário educacional da segunda metade dos anos 1910 e da década de 1920.

$\mathrm{Na}$ visão de Olavo Bilac, intelectual impregnado dos ímpetos nacionalistas do período, a escola deveria ser:

o primeiro reduto da defesa nacional; a menor falha no ensino e o menor descuido do Professor podem comprometer, sem remédio, a segurança do destino do país. $O$ Professor, quando professa, já não é um homem; a sua individualidade anula-se: ele é a Pátria, visível e palpável, raciocinando no seu cérebro e falando pela sua boca. A palavra que ele dá ao discípulo, é como a hóstia que, no templo, o sacerdote dá ao comungante. É a eucaristia cívica. Na lição há a transubstanciação do corpo, do sangue, da alma de toda a nacionalidade (Olavo Bilac apud: SOUZA, 2009).

\section{Entre hinos e bandeiras: a expansão da educação primária santista e a questão nacional}

Os grupos escolares tiveram um papel preponderante na expansão do ensino primário em São Paulo. A disseminação desse modelo, criado no final do século XIX no Estado e que serviria de exemplo para a configuração de outros sistemas públicos estaduais, ocorreu acompanhando o desenvolvimento urbano e foi responsável pela instrução de crianças de vários setores sociais, especialmente camadas populares e segmentos das camadas médias da população. O início do século $\mathrm{XX}$ assistiria ao predomínio desse tipo de escola primária, em especial após 1908, com o desdobramento dos períodos que ampliaria substancialmente o número de vagas oferecidas.

No entanto, esse modelo escolar exigia altos investimentos, pois necessitava de espaços próprios e adequados, professores bem preparados e conhecedores das "modernas pedagogias", mobiliário moderno e materiais didáticos que permitissem a execução do que era concebido como mais avançado pedagogicamente no período. Amparados em legislação específica, os reformadores da instrução pública idealizavam uma escola em que a racionalidade e a uniformidade ordenassem os espaços e os comportamentos. Disciplina, obediência, classificação, ordem. A escola graduada que surgia refletia os dilemas de uma sociedade pretensamente democrática e republicana.

Em Santos, até meados da década de 1910, existiam apenas três grupos escolares: o Cesário Bastos, fundado em 1900, o Barnabé, criado dois anos depois e o Vila Macuco, de 1915. O público atendido por esses estabelecimentos, apesar da escassez das evidências, aponta para uma ampla presença de filhos de estrangeiros pertencentes à classe trabalhadora em seus bancos. O já citado censo de 1913 indicava que de uma população total de 88.967 habitantes, quase $40 \mathrm{mil}$ eram estrangeiros. Os contingentes europeus mais numerosos eram compostos por portugueses (23.055), espanhóis (8.343), e italianos (3.554). Entre portugueses e espanhóis, predominavam os operários, da construção civil e do porto, os 

nacionalidade nos grupos escolares da cidade de Santos

empregados do comércio e os negociantes.

Os primeiros registros encontrados sobre o público atendido pelos grupos escolares santistas são de 1912, no Cesário Bastos. Nesse material, com informações sobre as profissões dos pais de alunos da escola, operários, comerciários e negociantes representam a maioria (cerca de $72 \%$ ), justamente as atividades majoritariamente exercidas pelos ibéricos na cidade. Apenas na segunda metade da década de 1910 apareceriam dados específicos sobre a origem desses alunos. No Barnabé, em 1919, de 798 alunos matriculados, 526 eram filhos de estrangeiros, sendo mais relevante a incidência de portugueses, espanhóis e italianos. Em 1929, no Cesário Bastos, a história se repete. De 208 alunos matriculados, 81 eram filhos de portugueses, representando $38,9 \%$ dos pais de alunos contra $38,0 \%$ de pais brasileiros. No Vila Macuco, grupo escolar localizado em bairro tradicionalmente operário da cidade, os indícios comprovam essa tendência. Em suas fileiras, filhos de operários, principalmente portuários, e comerciantes estrangeiros. Os dados publicados no Anuário do Ensino do Estado de São Paulo de 1919 evidenciam e enfatizam essa característica. Entre os alunos do Vila Macuco, os filhos de estrangeiros somavam 479 crianças, enquanto havia 394 filhos de brasileiros.

As estatísticas da Diretoria de Instrução Pública de São Paulo em 1919 seriam condizentes com os dados apresentados pelo censo de 1920, feito na cidade de Santos. A marcante influência estrangeira, especialmente europeia, continuava muito forte. A população santista era de 102.589 habitantes, dos quais $35,6 \%$ eram estrangeiros.

$\mathrm{Na}$ sociedade fortemente marcada pelo nacionalismo que se engendrou no Brasil nas décadas de 1910 e 1920, a preocupação com a composição social notadamente estrangeira e com a assimilação de imigrantes vinculados à classe trabalhadora atribuiu à educação escolar novos papéis. $\mathrm{O}$ analfabetismo surgia como a grande chaga a ser combatida. Em 1916, no Rio de Janeiro, o já citado Olavo Bilac participaria da fundação da Liga de Defesa Nacional, agremiação de caráter nacionalista que teria entre suas bandeiras a propagação da educação popular, o ensino de língua pátria nas escolas estrangeiras e o combate ao analfabetismo. No ano seguinte, em São Paulo, seria criada a Liga Nacionalista de São Paulo, congregando elites políticas e intelectuais do período como Júlio de Mesquita, Sampaio Dória e Oscar Thompson, os dois últimos diretamente envolvidos nas políticas públicas ligadas à instrução nas primeiras décadas do século XX.

Em 1918, em carta a Oscar Thompson, Sampaio Dória expressaria sua preocupação ao afirmar que:

o maior mal do Brasil contemporâneo é a sua porcentagem assombrosa de analfabetos. $O$ analfabetismo das massas é incompatível com a civilização mais elementar. Um analfabeto e, sem exagero, uma unidade negativa no seio do povo: não assimila as formas do progresso, não desenvolve sua capacidade produtiva, é a matéria por excelência prestável aos excessos de todas as sedições e facilmente suplantada pelas raças mais cultas. Mas, nas democracias, o analfabetismo é o ventre maldito das maiores calamidades públicas, como na Rússia atual dos camponeses. Governo de origem popular $e$ ignorância rasa do povo são coisas que se chocam, se repulsam, se destroem, como as trevas e a luz, como o inferno e o céu. A alfabetização é, na paz, a questão nacional por excelência. Só pela solução dela o Brasil poderá assimilar o estrangeiro que aqui se instala em busca de fortuna esquiva. Do contrário é o nacionalismo que desaparecerá absorvido pela inteligência mais culta dos imigrantes (Anuário do Ensino do Estado de São Paulo, 1918).

O depoimento de Sampaio Dória evidencia aspectos relevantes do pensamento de parte da elite do país sobre as chamadas "questões nacionais". O analfabetismo como empecilho à modernidade e à civilização, o nacionalismo e a necessidade de incorporação do estrangeiro faziam parte das concepções e dos desejos de parcela significativa, pelo menos no que diz respeito à representação política, da classe dominante do país.

$\mathrm{Na}$ evocação nacionalista, as escolas estrangeiras passam a ser encaradas como um risco. Em 1917, escolas estrangeiras são fechadas no sul do país $\mathrm{e}$ as restrições a sua abertura e funcionamento aumentam em São Paulo. (SOUZA, 2009)

O imigrante, elemento considerado alheio à nacionalidade brasileira, precisava ser integrado. $\mathrm{O}$ povo, ignorante, analfabeto, risco à organização do trabalho e à ordem pública, precisava ser instruído.

Em 1920 seria executada a Reforma 
Sampaio Dória, visando a erradicação do analfabetismo e responsável pela reestruturação do sistema público de ensino paulista configurado no final do século XIX. Tendo como característica central a redução do ensino primário de quatro para dois anos de duração, a reforma propunha que o terceiro e o quarto anos do até então ensino primário correspondessem agora ao ensino médio. A Reforma de 1920 previa também a redistribuição dos professores dos $3^{\circ}$ e $4^{\circ}$ anos para as classes de alfabetização, a introdução do escotismo, o incentivo à educação moral e cívica, o desdobramento dos turnos nas escolas isoladas, a criação das delegacias de ensino e a ênfase na nacionalização do ensino.

A importância atribuída à alfabetização, embora fundamental para a sua compreensão, não esgota os esforços contidos na Reforma de 1920. O ensino moral e cívico e o escotismo teriam papel primordial para a formação do caráter nacional, instituindo nas crianças as "saudáveis noções" de amor à Pátria, de respeito à ordem estabelecida e de cumprimento de deveres. Ainda sob o efeito das mobilizações operárias e das greves, o ímpeto reformista enxergava na moralização do povo brasileiro a regeneração da República. $\mathrm{O}$ estudo de história e geografia, a ginástica, o ensino da língua materna, enfim, todo o processo educacional deveria ser pautado pela idéia de civismo.

Em 1919, no Anuário de Ensino do Estado de São Paulo, Oscar Thompson exemplifica essa concepção ao afirmar que essas disciplinas:

além do desenvolvimento físico que proporcionam, incutem-lhes hábitos de ordem, de perseverança e de obediência, apresentando-lhes, ainda, nitidamente, na hierarquia militar, um fac-simile $d a$ hierarquia social, onde a existência da própria sociedade, não pode deixar de haver governantes e governados (1919).

A alfabetização, pura e simples, não era o bastante. Era necessário incutir hábitos adequados à organização do trabalho e ao modelo de sociedade que se entendia como ideal naquele momento.

Em meio aos estilhaços das mobilizações operárias, propunha-se a assimilação do estrangeiro, a organização do trabalho e a ordem social. A intensa busca pela unidade e pela identidade nacional dissimulava a existência de uma população heterogênea e uma sociedade desigual. Nacionalidades, etnias, condições sociais e ideologias diversas. A visão negativa de um povo que precisava ser conduzido às Luzes encontrava na enraizada crença no poder transformador da educação o seu veículo.

O responsável por essa missão um tanto inglória, o professor, assistia a constantes interferências e prescrições feitas ao seu trabalho cotidiano. Naturalmente, e relembrando as perspectivas de Escolano (2005) e de Julia (2001) sobre cultura escolar, é preciso levar em consideração as resistências e os limites das imposições de condutas esperadas dos docentes no período.

Em ata de 1919 encontrada no grupo escolar Barnabé, o então diretor, Armando Bellagarde, deixa claro que aos docentes caberia o papel de execução de um programa produzido com esmero pelos reformadores paulistas. Sobre as aulas de geografia, instrui o diretor:

a primeira aula será dada com auxílio dos mapas. Em seguida, os alunos tomarão nota em seus cadernos dos dados que precisam ser aprendidos. Na terceira aula, serão chamados alguns alunos para mostrar nos mapas o que aprenderam.

As recomendações de Bellagarde em relação às aulas de caligrafia são ainda mais sintomáticas. Além das prescrições comuns aos outros professores, o diretor enfatiza a importância do ensino moral e cívico:

é preferivel fazer poucas linhas a encher rapidamente os cadernos. Os trabalhos de caligrafia são os que maior atenção exigem os alunos e, para obrigá-los a se aplicarem a melhorar a letra, recomendo que façam as notas dessa matéria influir nas médias semanais. No caderno em branco, as sentenças a copiar devem ser preferencialmente de fundo cívico.

Exemplo:

Amemos com ardor a nossa Pátria.

As "recomendações" e exigências não paravam por aí. Ao docente cabia também o papel de controle dos alunos. A ordem disciplinar imposta aos alunos passava pelo asseio, pela obediência e pelos castigos. Tudo isso sobre o olhar atento e vigilante do professor. Ressaltando a importância da disciplina, o diretor questiona para na sequência 
responder:

Como conseguir uma boa disciplina? A disciplina depende exclusivamente do professor. Se ele trabalha com método, seguindo o programa, fazendo questão de ensinar, a classe ocupada seria sempre disciplinada. (...) Nas aulas, tratando de higiene, deveis falar francamente desta modalidade educacional: hábitos bons de educação do organismo.

Em uma cidade caracterizada pela existência de uma classe operária formada significativamente por pessoas de ascendência europeia, o interior dos grupos escolares refletia os anseios nacionalistas de incorporação do "outro".

A ênfase nos dispositivos de controle, na disciplina e nas noções de civismo evidencia a função atribuída à escola de que a "infância oferecia a vantagem de poder ser modelada desde o princípio de acordo com as necessidades da nova ordem que se instituía." (ENGUITA, 1989) Ao sistema público de ensino caberia esse papel em relação aos mais novos. À polícia e demais forças repressivas caberiam esse papel em relação aos adultos.

Nos materiais encontrados no Barnabé e nas informações obtidas sobre o grupo escolar Vila Macuco através de pesquisa feita por Márcio Brasil (2008), as comemorações e datas cívicas constituem parte importante desse processo. José Murilo de Carvalho (1990) já havia demonstrado de que forma se procurou construir uma determinada representação da história e do imaginário da República através da consagração de heróis e símbolos nacionais. Sobre essa questão, Carlos Monarcha destacaria que nas escolas públicas paulistas:

sob a proteção e inspiração da República alegorizada na figura feminina -, essas almas em formação através do estudo e da introspecção são envolvidas pelos símbolos nacionais - a bandeira, o hino nacional - , pelo culto dos heróis emergentes Tiradentes, Silva Jardim - e pela voga de livros de leitura de Felisberto de Carvalho e do livro Coração: diário de um aluno, de Edmundo de Amicis (MONARCHA, 1997).

No Barnabé, o diretor Armando Bellagarde corroborava essa tendência ao cobrar o envolvimento dos docentes e alunos nas comemorações dos "grandes acontecimentos de nossa Pátria". Era preciso "incutir nos alunos sentimentos de amor à Pátria e à Bandeira", desenvolvendo assim noções de "brasilidade". No Cesário Bastos, o então diretor Antonio Primo Ferreira destacava a importância do culto aos "heróis da República" e das noções de "civismo contra a perniciosa influência estrangeira."

No Grupo Escolar Vila Macuco, o empenho nas comemorações da Proclamação da República era cobrado anualmente. (BRASIL, 2008) No dia três de maio seria comemorado o Dia da Raça, para "propaganda da cultura física, da saúde e da raça." Entre hinos, bandeiras e heróis, buscava-se a unidade e a integração de uma sociedade multifacetada.

Em busca da nação brasileira, a educação primária paulista redefinia o seu caráter.

\section{Considerações Finais}

Nas décadas de 1910 e 1920, a escola volta ao centro dos debates sobre os rumos da nação. $\mathrm{O}$ analfabetismo e a "ameaça" estrangeira se tornam os alvos dos discursos e das políticas públicas educacionais do período. Em Santos, cidade de composição social notadamente ibérica e de atuante classe operária, a idéia de incorporação do estrangeiro, pela força policial ou pelos bancos escolares, ganha força. A Reforma de 1920, promovida por Sampaio Dória, alçou o analfabetismo a problema nacional por excelência e empecilho ao desenvolvimento do país. A importância atribuída à alfabetização, embora fundamental para a sua compreensão, não esgota os esforços contidos na Reforma de 1920. As noções de civismo teriam papel primordial para a formação do caráter nacional, instituindo nas crianças as concepções de amor à Pátria, de respeito à ordem estabelecida e de cumprimento de deveres. Ainda sob o efeito das mobilizações operárias e das greves do período, o ímpeto reformista enxergava na moralização do povo brasileiro a reconstrução da República.

$\mathrm{O}$ grande número de estrangeiros e existência de um organizado e combativo movimento operário faz de Santos uma cidade singular para o estudo do impacto das políticas educacionais desse momento. Muitos desses europeus, principalmente portugueses e espanhóis, fariam parte da classe operária local e teriam seus filhos como alunos dos grupos escolares da cidade. Em 1915, além dos grupos escolares Cesário Bastos 
e Barnabé, seria inaugurado um novo grupo escolar, o Vila Macuco, localizado em bairro operário da cidade. Nas três escolas, o número de filhos de imigrantes era superior ao número de filhos de brasileiros. Em meio às greves operárias e ao discurso nacionalista que acompanhou a Primeira Guerra Mundial, a incorporação da população estrangeira se torna fator primordial à constituição da nacionalidade brasileira.

A ênfase nos dispositivos de controle, de disciplina e nas noções de civismo norteava o trabalho que deveria ser desenvolvido nas escolas. As comemorações de datas cívicas, o culto à bandeira e aos hinos e a exaltação de símbolos e heróis nacionais se tornavam prescrições diárias ao trabalho docente e ao comportamento esperado dos alunos. Em uma sociedade heterogênea e diversa, buscava-se a unidade e a integração.

\section{Referências}

BRASIL, Márcio. O Grupo Escolar de Visconde de São Leopoldo e a escolarização de Vila Macuco durante a Primeira República. Dissertação de Mestrado, Programa de Educação, Universidade Católica de Santos, Santos/SP, 2008.

CARVAlHO, José Murilo de. A formação das almas: o imaginário da República no Brasil. São Paulo: Companhia das Letras, 1990.

ENGUITA, Mariano F. A Face Oculta da Escola. Porto Alegre: Artes Médicas, 1989.

ESCOLANO, Benito A. Las Culturas de la Escuela en España: Tres Cortes Historiográficos. Pro-Posições (pp. 41-63), Campinas, SP, vol. 16, n. 1 (46), jan./abr, 2005.

GITAHY, Maria Lucia. Ventos do mar: trabalhadores do porto, movimento operário e cultura urbana. São Paulo: Editora UNESP, 1992.

GONÇALVES, Alcindo. Lutas e Sonhos: cultura política e hegemonia progressista em Santos (1945 - 1962). São Paulo: Editora da Universidade Estadual Paulista, 1995.

JULIA, Dominique. A Cultura Escolar como Objeto Histórico. Revista Brasileira de História da Educação. Revista da Sociedade Brasileira de História da Educação (pp. 9-43). Campinas, SP, n. 1, jan./jun, 2001.

MARAM, Sheldon L. Anarquistas, imigrantes e o movimento operário brasileiro (1890-1920). Rio de Janeiro: Paz e Terra, 1979.

MONARCHA, Carlos. Arquitetura escolar republicana: a escola normal da praça e a construção de uma imagem de criança. In: FREITAS, Marcos. C. de (org.). História Social da Infância no Brasil. (pp. 101-140). São Paulo: Cortez e USP-IFAN, 1997.

SARTI, Ingrid. Porto Vermelho. Rio de Janeiro: Paz e Terra, 1981.

SILVA, Fernando Teixeira. Operários sem patrões: Os trabalhadores da cidade de Santos no entreguerras. Campinas, SP: Editora UNICAMP, 2003.

SOUZA, Rosa Fátima de. Alicerces da Pátria: História da escola primária no estado de São Paulo (1890 - 1976). Campinas, SP: Mercado das Letras, 2009.

THOMPSON, E.P. A formação da classe operária inglesa, 1: a árvore da liberdade. $6^{\circ}$ Ed. São Paulo: Paz e Terra, 2011.

Sobre o autor:

André Luiz Rodrigues Carreira: Graduado em História e Mestre em Educação pela Universidade Católica de Santos.

Recebido em 27/03/2014

Aprovado em 27/05/2014 